\title{
EVALUATION OF RED CHITTAGONG COWS BASED ON TEST DAY MILK PRODUCTION
}

\author{
M. S. A. Reza, A. K. F. H. Bhuiyan, M. A. Habib and T. Rabeya \\ Department of Animal Breeding \& Genetics, Bangladesh Agricultural University \\ Mymensingh-2202, Bangladesh
}

\begin{abstract}
The merit of Red Chittagong cows-a promising indigenous cattle genetic resource of Bangladesh was evaluated by using test day milk yield records of total 41 individuals. The data were collected from the Nucleus Herd of Red Chittagong (RC) cattle maintained at Bangladesh Agricultural University, Mymensingh from June, 2007 to October, 2008 under supervised animal recording system along with the previously recorded data from 2005 was also taken into consideration. Data were then analyzed for evaluating the cows based on lactation yield and average daily milk yield. Average lactation yield and daily milk yield were $453.86 \pm 59.61$ and $1.99 \pm 0.14 \mathrm{~kg}$, respectively. The highest lactation yield $(538.04 \mathrm{~kg})$ and daily milk yield $(2.3 \mathrm{~kg})$ was found in $4^{\text {th }}$ and $5^{\text {th }}$ lactation, respectively. The most probable producing ability (MPPA) of RC cows was calculated by using the test day records and then the animals were ranked on the basis of their MPPA value. For MPPA calculation two methods were followed; cow's repeated lactation performance $\left(\mathrm{MPPA}^{1}\right)$ and within lactation repeated test day records and averaged $\left(\mathrm{MPPA}^{2}\right)$. The highest MPPA for lactation yield was shown by the cow no. $36(645.61 \mathrm{~kg})$ and the highest MPPA ${ }^{1}$ and MPPA $^{2}$ for daily milk yield were 2.83 and $3.46 \mathrm{~kg}$, respectively for cow no. 03. The result of this study suggests that test-day yields may well be used for genetic evaluation of cows to make recurrent selection decision in cattle breeding programs.
\end{abstract}

Key words : Test day milk production, MPPA, Recurrent selection

\section{INTRODUCTION}

Livestock is an integral part of agricultural farming system in Bangladesh, contributing more than $2.95 \%$ to the national GDP (DLS, 2008). The total number of cattle population is about 22.78 million (DLS, 2007). About $25 \%$ people of the country are directly engaged in livestock and poultry business (DLS, 2008). The growth rate of this sector in GDP is about $7.23 \%$ (DLS, 2008). The average daily milk consumption is $42 \mathrm{ml}$ per day/person against a recommended allowance of $250 \mathrm{ml} /$ day. Bangladesh would currently need to import or produce five times its current production if it is to meet the World Health Organization recommended daily requirement.

Red Chittagong (RC) cattle is a distinct variety of indigenous cattle found more or less everywhere in Chittagong district and Chittagong Hill Tract region but rare in other parts 
of Bangladesh having some good features like; capable to adopt hot and humid climate and any kind of adverse situation, more resistance to diseases and parasites, need less input, ease to handle, efficient reproductive performance etc. Although milk production of RC cattle is low, but comparatively better than any other non-descript indigenous cattle found everywhere in Bangladesh.

Science-led dairy production requires recording system especially milk recording. In developed world usual practice in milk recording is that farms are visited every 3-4 weeks by official recorders, who record evening and morning milk yields called 'Test Day' milk recording and takes samples for chemical analysis to estimate fat and protein contents. Test day results, expected lactation yields, completed lactation yields, breeding values, farm averages, service and calving dates, calving intervals, and management and feeding recommendations are sent to the farmers shortly after the test. Total lactation yields can be calculated by multiplying a test-day yield by the numbers of days in the period of which that day is the centre; these products are summed to give the lactation yield. The first test period runs from a few days after calving to the beginning of the second period, and the last period runs from the end of the preceding period to the end of the lactation. But in developing countries situations where animal breeding infrastructure and manpower are most limiting, use of part lactation milk production recording for genetic evaluation of dairy cattle is more essential (Udo et al., 1994).

In most developing countries including Bangladesh such kind of analysis has not yet been carried out particularly on indigenous cattle. Moreover, evaluation of dairy cattle based on part lactation milk production data has not yet been attempted in Bangladesh. Therefore, the present study was aimed to evaluate RC cows for milk yield using their multiple lactation and test day milk production records.

\section{MATERIALS AND METHODS}

The use of test day (TD) records depends on the heritability and genetic correlations with 305- day lactation period. The main purpose of the present study was to evaluate RC cattle using their TD milk yield records. The possibility of using TD records for cow evaluation instead of 305-day was also investigated.

\section{Source of data}

Data consisted of TD milk yield of RC cows that calved first from 2004 to 2008 and were obtained from the data recorded at the Nucleus Herd of USDA funded Red Chittagong Cattle Project at the Department of Animal Breeding and Genetics, Bangladesh Agricultural University (BAU), Mymensingh.

Fifteen days interval milk records (morning plus afternoon yields on the same day) from cows in the first to fifth lactations under supervised animal recording systems were used. Data only from complete lactation were considered. 
The TD information was stored in data files that included cow identification number, calving date, days in milk (DIM), daily milk yield (DMY), total lactation yield (LY) and lactation length (LL). Data were included only those animals which had their first TD between 4 and 7 days after calving and interval between their consecutive tests were between 15 days following Shadparvar and Yazdanshenas (2005).

\section{Traits considered}

Economically important traits of RC cows i.e. lactation yield (LY) and daily milk yield (DMY) were taken into consideration to evaluate cows based on their MPPA.

\section{Lactation yield}

No standardization was done for LY. The total milk yield of a cow throughout the lactation period was taken as LY and was measured in kilogram.

\section{Daily milk yield}

The DMY was measured by taking 15 day interval test day methods.

\section{Most probable producing ability}

Breeders want to select animals which will have the biggest future records of performance using heritability and repeatability of the trait. Repeatability indicates the proportion of phenotypic variation for repeatable trait which is caused by genetic and permanent environmental variations. Lush (1963) suggested the following formula for calculating MPPA or to adjust the records of individuals with different number of records on the same basis. For milk yield of RC cows, repeated records were used to determine MPPA by using the following formula:

For multiple records of performance

MPPA $=$ herd average $+\frac{n r}{1+(n-1) r}$ (individual average - herd average)

where, $n=$ no. of observations, $r=$ repeatability of the trait considered.

MPPA was calculated using the following two methods :

\section{Method 1}

The average DMY of RC cow in different lactations was taken into consideration. So, cows with more than one lactation performance consisted of the data for this method.

\section{Method 2}

In this method, repeated test day milk yield records of a cow in different lactations were used to calculate her MPPA. The test day based MPPA of cows were then averaged to have single MPPA value of each cow in this method.

However, for evaluation of RC cows based on lactation yield only Method 1 was employed for MPPA calculation. 


\section{Ranking of cows based of MPPAs}

After calculation of the MPPAs for LY and DMY the cows were ranked on the basis of the MPPA values. These rankings were then used to make recurrent selection decision in the RC cattle nucleus herd.

\section{RESULTS}

Data were collected from a total no. of 41 milking animals whose LY and TD milk yield record at 15-days interval were available. The MPPA of the animals for the traits were calculated and then subsequently animals were ranked on the basic of their genetic merit.

\section{Lactation yield}

The estimated means with standard errors (SE) for LY of RC cows are presented in Table 1. The average LY of RC cows herd was $453.86 \mathrm{~kg}$. The average LY was also calculated according to different parity which is also shown in Table 1 . The highest LY was found on $4^{\text {th }}$ parity $(538.04 \mathrm{~kg})$.

Table 1. Average lactation yield and daily milk yield in different lactations

\begin{tabular}{c|cc}
\hline \multirow{2}{*}{ Lactation no. } & \multicolumn{2}{|c}{ Mean \pm SE $(\mathrm{Kg})$} \\
\cline { 2 - 3 } & Lactation yield & Daily milk yield \\
\hline 1 & $482.67 \pm 80.06$ & $1.85 \pm 0.11$ \\
2 & $429.70 \pm 43.76$ & $1.78 \pm 0.08$ \\
3 & $466.07 \pm 36.25$ & $2.00 \pm 0.08$ \\
4 & $538.04 \pm 73.95$ & $2.02 \pm 0.13$ \\
5 & $352.82 \pm 64.03$ & $2.30 \pm 0.30$ \\
\hline Overall & $453.86 \pm 59.61$ & $1.99 \pm 0.14$ \\
\hline
\end{tabular}

\section{Daily milk yield}

The calculated means with SE for DMY of RC cows are presented in Table 1. The overall mean of DMY was $1.99 \mathrm{~kg}$. Highest DMY was observed on $5^{\text {th }}$ parity which was $2.3 \mathrm{~kg}$.

\section{Most probable producing ability}

The calculated MPPA of RC cows for the traits studied are presented below.

\section{MPPA for lactation yield}

Table 2 shows the calculated MPPAs for lactation yield of RC cows based on 5 LY. The MPPA for LY was highest $(645.61 \mathrm{~kg})$ for cow bearing I.D. no. 36 . The $2^{\text {nd }}$ highest MPPA value was observed in the cow no. 09 which was $613.11 \mathrm{~kg}$. whereas, the lowest MPPA value among the 17 animals was $352.22 \mathrm{~kg}$ bearing cow I.D. no. 40 . 
Table 2. MPPA of RC cows for lactation yield

\begin{tabular}{|c|c|c|c|c|c|c|c|}
\hline \multirow[t]{2}{*}{ Cow } & \multicolumn{5}{|c|}{ Lactation yield } & \multirow[t]{2}{*}{$\mathrm{MPPA}^{1}$} & \multirow[t]{2}{*}{ Rank } \\
\hline & Lac 1 & Lac 2 & Lac 3 & Lac 4 & Lac 5 & & \\
\hline 02 & & 551.85 & 585.12 & & & 533.45 & 05 \\
\hline 08 & & & & 557.55 & 474.24 & 503.40 & 07 \\
\hline 09 & & & & 786.38 & 630.48 & 613.11 & 02 \\
\hline 10 & & & & 465.5 & 683.4 & 536.74 & 04 \\
\hline 12 & & & & 549.0 & 555.12 & 523.98 & 06 \\
\hline 13 & & & & 399.84 & 561.0 & 483.19 & 09 \\
\hline 14 & & & & 257.28 & 554.4 & 440.64 & 13 \\
\hline 17 & & & 392.71 & 428.12 & 251.37 & 400.52 & 16 \\
\hline 18 & & & 201.25 & 546.48 & & 479.77 & 10 \\
\hline 22 & & 448.35 & 503.73 & 432.60 & & 470.13 & 12 \\
\hline 24 & & 536.24 & 408.48 & & & 478.55 & 11 \\
\hline 26 & 630.0 & 560.5 & & & & 548.59 & 03 \\
\hline 27 & 474.72 & 496.96 & & & & 486.23 & 08 \\
\hline 30 & 372.13 & 371.07 & & & & 421.11 & 15 \\
\hline 35 & 460.20 & 324.94 & & & & 432.54 & 14 \\
\hline 36 & 899.84 & 631.06 & & & & 645.61 & 01 \\
\hline 40 & 292.60 & 208.90 & & & & 352.22 & 17 \\
\hline
\end{tabular}

\section{MPPA for daily milk yield}

Estimated MPPA for DMY of each individual are given in the Table 3. The cow having ID no. 03 had the highest calculated MPPA value $(2.83$ and $3.46 \mathrm{~kg})$ for DMY among the considered 41 individuals. The $2^{\text {nd }}$ highest MPPAs value among the animals was 2.82 and $3.46 \mathrm{~kg}$ calculated by two methods by the cow bearing ID No. 04 .

\section{Ranking of animals}

MPPA for LY was highest $(645.61 \mathrm{~kg})$ for cow bearing ID no. 36. The cows with ID no. 02 , 09, 10 and 26 possessed the top ranking MPPA values (Table 2) among the cows.

From Table 3 it is observed that DMY in most cases the cow bearing ID no. 03, 04, 07, 14, $24,25,26,27,35,39$ and 50 possessed the same rank (position) in both systems of calculating MPPA value. The cow having ID no. 03 had the highest MPPA value and ranked first in the both systems. Among the experimental animals, cow bearing ID no. 03, $04,05,07,08,09,12,23,28$ and 36 showed their superiority for the trait of DMY. On the other hand, the cow bearing ID no. 40 occupied the last position (41 $\left.{ }^{\text {st }}\right)$ for MPPA $^{1}$ (1.59) and the cow with ID no.44 secured the last position for MPPA² (1.27) calculation system. 
Table 3. MPPA of RC cows for daily milk yield

\begin{tabular}{|c|c|c|c|c|}
\hline Cow & MPPA $^{1}$ & Rank & $\mathrm{MPPA}^{2}$ & Rank \\
\hline 01 & 1.95 & 20 & 1.90 & 23 \\
\hline 02 & 1.91 & 27 & 1.87 & 25 \\
\hline 03 & 2.83 & 01 & 3.46 & 01 \\
\hline 04 & 2.82 & 02 & 3.46 & 02 \\
\hline 05 & 2.10 & 08 & 2.27 & 07 \\
\hline 06 & 1.93 & 22 & 1.84 & 26 \\
\hline 07 & 2.23 & 04 & 2.61 & 04 \\
\hline 08 & 2.11 & 05 & 2.29 & 06 \\
\hline 09 & 2.01 & 14 & 2.70 & 03 \\
\hline 10 & 1.93 & 23 & 2.07 & 14 \\
\hline 11 & 2. 00 & 16 & 2.02 & 17 \\
\hline 12 & 2.09 & 09 & 2.17 & 11 \\
\hline 13 & 1.93 & 24 & 1.91 & 22 \\
\hline 14 & 1.79 & 34 & 1.69 & 34 \\
\hline 15 & 1.93 & 25 & 1.88 & 24 \\
\hline 16 & 2.02 & 12 & 2.08 & 13 \\
\hline 17 & 1.85 & 30 & 1.79 & 28 \\
\hline 18 & 1.82 & 33 & 1.74 & 32 \\
\hline 20 & 2.02 & 13 & 2.02 & 16 \\
\hline 21 & 2. 00 & 17 & 1.96 & 19 \\
\hline 22 & 1.96 & 19 & 1.95 & 20 \\
\hline 23 & 2.11 & 06 & 2.20 & 10 \\
\hline 24 & 1.79 & 35 & 1.69 & 35 \\
\hline 25 & 1.94 & 21 & 1.91 & 21 \\
\hline 26 & 1.97 & 18 & 1.97 & 18 \\
\hline 27 & 1.84 & 31 & 1.74 & 31 \\
\hline 28 & 2.07 & 10 & 2.21 & 08 \\
\hline 29 & 2.03 & 11 & 2.09 & 12 \\
\hline 30 & 1.84 & 32 & 1.74 & 33 \\
\hline 31 & 1.72 & 38 & 1.32 & 40 \\
\hline 32 & 1.91 & 28 & 1.79 & 29 \\
\hline 34 & 2.11 & 07 & 2.21 & 09 \\
\hline 35 & 1.74 & 37 & 1.56 & 37 \\
\hline 36 & 2.29 & 03 & 2.53 & 05 \\
\hline 37 & 1.90 & 29 & 1.78 & 30 \\
\hline 39 & 1.79 & 36 & 1.64 & 36 \\
\hline 40 & 1.59 & 41 & 1.39 & 38 \\
\hline 42 & 1.93 & 26 & 1.84 & 27 \\
\hline 44 & 1.70 & 39 & 1.27 & 41 \\
\hline 49 & 1.63 & 40 & 1.37 & 39 \\
\hline 50 & 2.01 & 15 & 2.03 & 15 \\
\hline
\end{tabular}




\section{DISCUSSION}

The use of TD models avoids the necessity of extending short lactations on culled animals and animals with records in progress. The disadvantages of TD model include computational difficulties associated with analyzing much larger datasets and the need to estimate many more parameters than in a traditional 305-d lactation model. Several different models have been proposed to model the trajectory of the lactation, including so-called "biological functions", various polynomials and character process models. At present, there is not universal agreement on which models to use in routine prediction of breeding values and better methods to compare models are desirable. Obtaining accurate estimates of the dispersion parameters to use in TD model remains a challenge.

\section{Lactation yield (LY)}

The average LY along with SE according to parity of cows are depicted in Table 1 . The overall LY was $453.86 \mathrm{~kg}$ for Red Chittagong cows. A higher LY was reported by several previous investigations. Alam et al. (2007) reported $516.94 \mathrm{~kg}$ and Habib et al. (2003) found 661.16 liters whereas Hasnath (1974) showed $727.0 \mathrm{~kg}$ per LY in RC cows. Deb (2004) found $700.07 \mathrm{~kg}$ in Local cattle of Bangladesh. Hossain et al. (2002) quoted $540.7 \mathrm{~kg}$ in Local cattle which is also higher than the findings of the current study. This low performance might be due to the environmental effects on the animal performance when the experiment was being carried out such as age, managemental decision, feeding regime, season, stage of lactation, population size etc.

\section{Daily milk yield}

The overall average DMY was $1.99 \mathrm{~kg}$ for RC cows. Result obtained from Alam et al. (2007) was $2.16 \mathrm{~kg}$. Habib et al. (2003) reported that average DMY of RC cows was 2.55 liter. Khan et al. (2000) also observed the average DMY of RC cows as $2.0 \mathrm{~kg}$ and $1.80 \mathrm{~kg}$ in farm and rural condition, respectively. Mondal (1998) found $2.46 \mathrm{~kg}$ milk yield per day of RC cows as well. From these results it is apparent that the production of RC is somehow similar to each other.

\section{MPPA and ranking of cows}

MPPAs were calculated by using the said formula for each animal of the experiment and ranked them according to their genetic worth (Table 2 and 3). In the present study, the cows' genetic merit for average DMY was evaluated using their multiple lactation records. The cows born in a specific year was considered to be contemporary to each other. Calculation of deviation in performance of individual cows from the reference mean (contemporary group average) ranked the animals on their genetic basis for single records. These individual deviations were then summed and averaged which cancelled out temporary environmental effects specific to each lactation average.

In long generation interval bearing species like cattle, the animals in any farm need to perform a couple of parities or calving and this necessitates the breeders to practice recurrent selection in their herd. Therefore, the evaluated MPPAs of RC cows would have 
been used to take recurrent selection decision. Moreover, half of the evaluated MPPAs of the cows could be assigned to their calves as their genetic merit for DMY. Similarly, predicted MPPAs of the cow's collateral female relatives can be assigned to rank the calves genetically. Furthermore, during selection and breeding program for improvement in the next generation this animal should get top priority if these traits are considered where their MPPA value were medium. The other animals should also get priority according to their ranking consecutively. This will ultimately help to take early selection decision in the herd thus enhancing herd profitability.

From the results of the study it became clear that the estimated MPPAs were in agreement with previous estimates carried on different established breeds and indigenous cattle elsewhere. The method is needed most for things which are least constant from one time to another in the animal's life. Much of the gain from using it comes with the second records, but if $\mathrm{r}$ is small the gain from waiting for a third or even a fourth record may be considerable.

The method does not help at all to keep the breeder from being deceived by permanent effects of environment, such as permanent stunting when young, nor by the consequences of dominance and complex gene interactions. Placing much reliance on selecting animals by their lifetime averages will naturally lead men generally to buy breeding stock from herds which they know well and in which they have had several opportunities to study the animals.

This piece of research will be very much needed to evaluate RC cows genetic merit on the most important trait, milk production. Finally, it can be pointed out that according to MPPAs evaluated by the experiment, the RC cows having the higher value can be kept for the further breeding programme.

\section{CONCLUSION}

From the findings of the present study it may be concluded that the milk production level of available genetic resources and other indigenous cattle of Bangladesh is far below from expectation. The MPPAs of the RC cows could be used to take recurrent selection decision and also these breeding values of cows could be assigned to their genetic merit for milk yield to decide on replacement animal selection.

\section{REFERENCES}

Alam, M., Bhuiyan, A. K. F. H., Ali, A. and Mamun, A. 2007. Genetic analysis of birth weight and milk production of Red Chittagong cattle of Bangladesh. Bang. J. Anim. Sci., 36(1\&2): 24-32.

Deb, G. K. 2004. Estimation of genetic parameters for some quantitative traits in dairy cattle of Bangladesh. M. S. Thesis, Department of Animal Breeding \& Genetics, Bangladesh Agricultural University, Mymensingh.

Department of Livestock Services (DLS). 2007. Annual Report 2006-2007. Ministry of Fisheries and Livestock, Government of Bangladesh, Dhaka, Bangladesh. 
Department of Livestock Services (DLS). 2008. Annual Report 2007-2008. Ministry of Fisheries and Livestock, Government of Bangladesh, Dhaka, Bangladesh.

Habib, M. A., Bhuiyan, A. K. F. H., Bhuiyan, M. S. A. and Khan, A. A. 2003. Performance of Red Chittagong cattle in Bangladesh Agricultural University dairy farm. Bang. J. Anim. Sci., 32(1-2): 101-108.

Hasnath, M. A. 1974. Studies on crossbred cattle, Research Bulletin. Department of Animal Breeding and Genetics, BAU, Mymensingh.

Hossain, K. B., Takayanagi, S., Miyake, T., Bhuiyan, A. K. F. H. and Sasaki, Y. 2002. Statistical genetic studies on cattle breeding for dairy productivity in Bangladesh: II. Estimation of reciprocal and heterosis effects and optimum crossbreeding system between the Local breed and exotic breeds for milk performance. Asian-Aust. J. of Anim. Sci., 15(6): 777-782.

Khan, M. K. I., Huque, K .S., Miah, A. G. and Khatun, M. J. 2000. Study on the performance of Red Chittagong cows under different production system. Pakistan Journal of Biological Sciences, 3(2): 318-319.

Lush J. L. 1963. Animal Breeding Plans. Iowa State University Press, Ames, Iowa, USA.

Mandal, A. and Sachdeva, G. K. 1999. Genetic analysis of birth weight of calves in cattle. Indian Journal of Animal Sciences, 69(11): 979-980.

Shadparvar A. A. and Yazdanshenas M. S. 2005. Genetic parameters of milk yield and milk fat percentage test day records of Iranian Holstein cows. Asian-Aust. J. of Anim. Sci., 18(9): 1231-1236.

Udo H. M. J. 1994. Use of Ruminant Genetic Resources in The Tropics, Department of Animal Production Systems, Wageningen Agricultural University. 